\title{
Saving for retirement: rules of thumb
}

\author{
S. D. Hyams*, A. E. Smith, C. M. Squirrell, G. J. Warren, O. H. Warren and P. J. Willetts \\ [Presented to the Institute \& Faculty of Actuaries, Staple Inn, London, 20 May 2019] \\ ${ }^{\star}$ Correspondence to: Stephen Hyams, 16 Atwood Avenue, Richmond, Surrey TW9 4HG, UK. E-mail: stephen@hyams.co
}

\begin{abstract}
Rules of thumb (RoTs) are proposed as a means of promoting higher levels of Defined Contribution (DC) pension saving and to help stimulate debate about the high and uncertain cost of pension provision, leading to the development of solutions. The Lifetime Pension Contribution (LPC) tells young people what pension contribution is required over a full working life to achieve a decent retirement income, calculated as $23 \%$ of average UK earnings. Another RoT is that each $1 \%$ of earnings provides a pension of $1.5 \%$ of earnings. Other RoTs show how costs vary by retirement age and if the saver's retirement planning is on track. The current high cost of pensions is partly due to low interest rates and the inefficiencies of the DC market, with inadequate bulk purchasing power and risk sharing. RoTs might help encourage higher employer contributions, either through automatic enrolment or on a voluntary basis.
\end{abstract}

Keywords: Defined Contribution Pensions; Automatic Enrolment; Rules of Thumb; Heuristics; Pension Contribution Rates; Saving for Retirement

\section{Summary with Recommendations}

1. This paper has been prepared by the "Saving for Retirement Working Party" of the Institute \& Faculty of Actuaries (IFoA).

2. The IFoA has advocated a "bottom-up", or outcomes-based approach to pension provision, and the Pension \& Lifetime Savings Association (PLSA) are also adopting that approach in the development of their Retirement Income Targets (RITs). We have addressed the question of how much needs to be saved in order to achieve a given target pension.

3. While personalised tools will be crucial in helping consumers answer that question, we believe that rules of thumb (RoTs) also have a role to play, for the many consumers who will only be relying on pension saving to achieve their target income. This excludes (a) those on relatively low incomes who are likely to be heavily reliant on State pension plus any modest Defined Contribution (DC) benefits built up through automatic enrolment and (b) those with more substantial financial means who can afford financial advice if required.

4. We have developed some suggestions accordingly. RoTs do not necessarily provide a means of achieving the best outcome for every individual, but aim to provide a guide that is appropriate for most of the target group most of the time.

\section{Lifetime Pension Contribution}

A Lifetime Pension Contribution (LPC), aimed primarily at young consumers (in their 20's), would provide a guide to the monthly contribution required over a full working life to achieve a reasonable retirement income when combined with the State pension.

\footnotetext{
(C) Institute and Faculty of Actuaries 2020. This is an Open Access article, distributed under the terms of the Creative Commons Attribution licence (http://creativecommons.org/licenses/by/4.0/), which permits unrestricted re-use, distribution, and reproduction in any medium, provided the original work is properly cited.
} 
5. All our RoTs, including the LPC, assume contributions commence at age 22, so they are internally consistent.

6. We envisage that the LPC (and the RITs) would increase annually in line with Average Weekly Earnings (AWE) in order to maintain their value relative to general earnings growth, while noting this is part of the current "triple lock" for increases in State pension.

7. We derived an illustrative LPC based on a pre-tax RIT of $£ 18,000$ (about $2 / 3^{\text {rd }}$ of annualised AWE), inclusive of State pension and payable from State Pension Age (SPA) of 68, which we believe is a reasonable target pension for the average consumer to aspire to. However, the calculated LPC is $£ 525$ per month, or the monthly equivalent of around $23 \%$ of AWE which, even after allowing for the employer's contribution and tax relief, is likely to be unaffordable for many consumers, leading to disengagement. We considered later the implications so arising.

\section{Retiring Later than Age 68}

8. If the consumer continues to make DC contributions beyond age 68 and defers drawing State pension until the DC pension commences, a simple adjustment to the LPC can indicate the reduction in monthly contribution required to achieve the same RIT of $£ 18,000$ at the later age. For example, with a LPC of $£ 525$ the deduction is $£ 55$ for each year between 68 and retirement age. The required monthly contribution for retirement at age 71 is there-

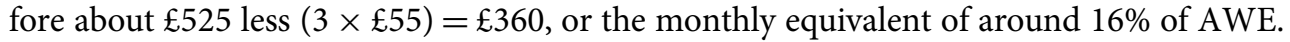

\section{Rules of Thumb for Target Pension}

9. Another RoT aimed primarily at young consumers is to estimate the target pension at age 68 (before allowing for State pension) based on their current level of contributions (inclusive of any employer contribution). The RoT is target annual pension $=1.5$ times the current annual contribution. This can be used to test the adequacy of current contributions and make adjustments accordingly.

10. For retirement at other ages, the multiple changes, e.g. 1.5 becomes 1.7 (for retirement at 70) and 1.2 (for retirement at 65).

\section{Rules of Thumb for Older Consumers}

11. Older consumers can use the above RoTs, in conjunction with another that helps them check the adequacy of their accumulated DC funds against a "benchmark fund", so that action can be taken accordingly. For example, if aged 41-50, the benchmark fund is calculated as the current annual contribution $\times($ age -20$)$. So if a consumer aged 50 was contributing the LPC of $£ 525$ per month, the expected DC fund at age 50 would be derived as $\mathfrak{E} 525 \times 12 \times(50-20)=\mathfrak{E} 189,000$. If the actual fund were less than this benchmark, the consumer could consider paying additional contributions to bridge the gap, as well as continuing to contribute the LPC.

12. We strongly support the development of the Pensions Dashboard, which would facilitate the comparison of what may be multiple DC funds against a consumer's benchmark fund. Indeed, one idea would be to show a benchmark fund on the Dashboard.

13. On nearing retirement, it becomes increasingly important to adopt a personalised approach, taking into account individual circumstances. This will need emphasising as part of the communication of RoTs. 


\section{Variation in Contributions}

14. Our RoTs assume consumers will contribute a constant percentage of earnings from age 22. In practice contribution patterns will vary; for example, some may wish to contribute lower amounts initially and correspondingly larger amounts in later years. The RoTs can still be used, with the benchmark funds helping to guide people over time.

15. Adjusting contributions to reflect investment experience enables a consumer to narrow the range of uncertainty in retirement income, but creates a variable and uncertain preretirement income.

This is one example of the trade-offs involved, and we suggest more work is undertaken to develop further RoTs to assist consumers in managing their consumption over the entire period pre- and post-retirement.

\section{Affordability}

16. The minimum employer contribution under automatic enrolment (A/E) is 3\% from April 2019. A phased increase in employer contribution to 6\% (with total contributions rising to $12 \%$ ), as proposed by the PLSA, would provide some assistance in making DC pension provision more affordable for consumers. We also support the Government's proposal to remove the lower earnings threshold when calculating qualifying earnings. Widening the scope of A/E to include the self-employed should also be a priority.

17. A/E was never intended to be sufficient to provide an adequate retirement income, and our analysis suggests that would remain the case even after an increase in A/E contributions to $12 \%$. Additional voluntary contributions should therefore still be anticipated.

18. The LPC is sensitive to the choice of RIT; we used $£ 18,000$ by way of illustration. We believe the LPC should be based on an appropriate RIT, derived after widespread discussion, and that if the resulting monthly contribution is deemed unaffordable for general use, then the LPC should be reduced by assuming consumers work longer and retire later. This should be made clear to consumers so that their expectations are properly managed.

19. Part of the problem with affordability lies in the inefficiencies of the individual DC market. We therefore suggest there is a need to find ways to harness bulk purchasing powers, along with the benefits of pooling investment and mortality risks. This would make DC pension provision more affordable and predictable for the consumer. The growth of master trusts should lend itself to the development of such solutions, as would the introduction of collective DC schemes.

20. One aspect of particular concern is that the cost of individually purchased annuities is currently around 15-20\% higher than the terms typically available to defined benefit pension schemes for bulk purchase under a buy-in or buy-out.

21. Low interest rates are a major reason for the high cost of pension provision. While future rates cannot be predicted, the unravelling of the effects of quantitative easing (QE) should lead to an increase in interest rates, other things being equal. A rise in long-term interest rates could significantly reduce the cost of pension provision, e.g. an increase to say $4 \%$ p.a. from the current (March 2019) level of around 2\% p.a. would reduce the LPC, perhaps by around $30 \%$.

22. The issue of affordability is a serious one and requires widespread discussion. We believe the concept of the LPC can provide a useful platform for promoting such a debate, having regard to the various issues outlined above. 


\section{Rules of Thumb in Practice}

23. We see merit in developing a single LPC, in order to create the maximum impact. The LPC would act as a benchmark of pension cost, increasing annually in line with AWE and adjusted periodically for other factors, such as interest rate changes. Promoting the LPC in the national media would help cement it in the general psyche.

24. We suggest that market research is undertaken to test whether the RoTs, including the LPC, would be helpful. The research can also address the means of communicating the RoTs. This might include the development of an independently branded smartphone app to facilitate their use.

25. RoTs will be more effective if used in conjunction with "nudges", i.e. promoting actions at key "teachable" moments.

\section{Introduction}

1.1. The department of work \& pensions latest review of automatic enrolment $(\mathrm{A} / \mathrm{E})^{1}$ highlighted a number of inadequacies in the levels of DC retirement savings in the UK:

- Current saving levels present a substantial risk that the retirement expectations for a significant proportion of the working-age population will not be supported;

- Whilst more individuals than ever before are saving, they are not necessarily engaged with saving nor looking to take personal responsibility to plan, and save more, for their retirement;

- There are significant gaps in coverage of A/E, notably those in low-paid multiple parttime jobs, younger workers and the self-employed.

1.2. To help promote more engagement, the IFoA has argued for a "bottom-up" outcomesbased approach ${ }^{2}$. By focussing people's attention on their expected standard of living in retirement, it is hoped that they can then be encouraged to explore the level of contributions required to achieve their expectations ${ }^{3}$, and then take action by adjusting their contributions to an appropriate level.

1.3. This is consistent with the PLSA's consultation ${ }^{4}$ in which it advocated the development of RITs. The PLSAs final report ${ }^{5}$ confirmed its decision to commission work by a team at Loughborough University to develop a set of RITs. This is due to be finalised in mid-2019.

1.4. To support the development of RITs it will clearly be important to provide the tools necessary to enable people to determine how much to save in order to achieve their chosen RIT. Personalised tools will play a key role, including annual benefit statements and interactive modellers.

1.5. We also see a role for the provision of broad, generic guidance (or "RoTs") for those who do not engage with a more personalised approach. This is supported by the Pension Policy Institute (PPI) who note that people tend to manage their finances through shortcuts such as RoTs ${ }^{6}$, and are particularly open to behaviour change when an intervention is relevant to their current circumstances, referred to as "teachable moments" (such as moving home or getting married).

\footnotetext{
${ }^{1}$ Department of Work \& Pensions (2017) Automatic Enrolment Review: Maintaining the Momentum.

${ }^{2}$ Institute \& Faculty of Actuaries (2016) Assessing Adequacy of Retirement Income: a Bottom-Up Approach.

${ }^{3}$ Institute \& Faculty of Actuaries (2015) Saving for Retirement : Policy Briefing (see Priority 4).

${ }^{4}$ Pension \& Lifetime Savings Association (2017) Hitting the Target: Delivering Better Retirement Outcomes.

${ }^{5}$ Pension \& Lifetime Savings Association (2018) Hitting the Target: A Vision for Retirement Income Adequacy: Final Recommendations.

${ }^{6}$ Pension Policy Institute (2017) Consumer Engagement: The Role of Policy Through the Life Course.
} 
1.6. RoTs do not necessarily provide a means of achieving the best outcome for every individual $^{7}$, but aim to provide a guide that is appropriate for most of the target group most of the time. RoTs have been developed in New Zealand for helping consumers to decide how much income to draw from their DC funds in retirement ${ }^{8}$.

1.7. We have investigated how RoTs might be developed to support the RITs. Our analysis is aimed at a target audience described in the PLSA consultation, "In the many cases where people will only be relying on pension saving to achieve their target income, it will be possible to adopt and promote standard rules of thumb".

1.8. This excludes consumers for whom we envisage RoTs not being generally appropriate, namely (a) those on relatively low incomes who are likely to be heavily reliant on State pension plus any modest DC benefits built up through $\mathrm{A} / \mathrm{E}$ and (b) those with more substantial financial means who can afford financial advice if required.

1.9. The Financial Conduct Authority (FCA) has provided some useful thoughts on what makes a good RoT $^{9}$, listing six key criteria for success:

1. Factual \& objective: Is the rule evidence based? Does it meet a fundamental consumer need or is it product orientated?

2. Universal: Does it apply to most people? Will it transcend generations and economic periods?

3. Actionable: Does it lead the consumer to a specific action or decision? Is it relevant, believable and achievable?

4. Intuitive: Is it based on a widely accepted principle? Does it make sense to most people, without requiring complex calculations or concepts?

5. Simple and memorable: Is it articulated in a way that is easy to understand? Does it spark an interest when first heard?

6. Empowering: Does it use positive language that motivates action, rather than appearing condescending?

\section{Target Retirement Fund}

2.1. Determining the target fund at retirement is the first step in deriving the level of annual contributions needed prior to retirement.

2.2. The choice of RIT will be a major factor in determining the target fund. For illustration purposes, we have assumed that the consumer chooses a RIT of $£ 18,000$, on the basis that this is approximately two-thirds of annualised Average Weekly Earnings (AWE) of $£ 27,456^{10}$, and two-thirds is the Target Replacement Rate suggested by the Pensions Commission $^{11}$ at that level of earnings. There is considerable debate as to whether replacement rates are useful given the wide range of individual circumstances, but for present purposes this is a convenient starting point.

2.3. We have further assumed that the consumer will earn a full State pension of about $£ 8,500$, so that the retirement income required from the target fund is approximately $£ 9,500$ per year.

\footnotetext{
${ }^{7}$ Pension Policy Institute (2015) Myths and Rules of Thumb in Retirement Income.

${ }^{8}$ Retirement Income Interest Group of the New Zealand Society of Actuaries (2017) Decumulation Options in the New Zealand Market: How Rules of Thumb can help.

${ }^{9}$ Financial Conduct Authority (2017) Rules of Thumb and Nudges: Improving the Financial Well-Being of UK Consumers.

${ }^{10}$ Office for National Statistics as at October 2018.

${ }^{11}$ Pensions Commission (2005) A New Pension Settlement for the Twenty-First Century: Second Report.
} 
2.4. We also assumed that the RIT and State pension will increase annually in line with AWE in order to maintain their value in real terms (and noting AWE is part of the current "triple lock" for increases in State pension).

2.5. We have anticipated that each member of a household will aim to provide for their own RIT, with no contingent pension payable to a spouse or dependant after death. We recognise that many household costs are shared, and this might influence the choice of RIT, but each consumer needs their own RIT for planning purposes.

2.6. Finally, we have assumed the RIT is a gross amount, i.e. before deduction for tax.

\section{Retirement Age}

2.7. The age from when the retirement income is to commence is very significant, since an earlier commencement age will require higher contributions. A discrete retirement age is becoming much less common nowadays, with flexible working patterns and the removal of an employer's right to force its employees to retire by virtue of age. Nevertheless, an assumed single retirement age is the simplest way to define retirement objectives.

2.8. We have assumed that the consumer will retire at SPA, since the commencement of the State pension will make retirement much more affordable for our target group at this time.

\section{Retirement Objectives}

2.9. Given the options now available at retirement, as discussed in our review of the decumulation market ${ }^{12}$, we also need to consider the extent to which the consumer wishes to prioritise the following competing objectives:

(a) The target income will continue for life (security);

(b) The target income is protected against the impact of inflation (inflation protection);

(c) Value for money is achieved in the event of early death, or that specific legacy intentions are met (legacy needs);

(d) There is flexibility to vary the income to suit changing circumstances (flexibility);

(e) Whether the consumer has additional requirements at retirement, such as to pay off debt or finance a holiday or another major discretionary purchase (cash needs).

2.10. Can we choose a single measure of target fund at retirement that represents a fair balance of the above objectives (noting that objectives may be unclear for young consumers and can change over time)? If we could, this would facilitate the development of RoTs.

2.11. We explore this further in Appendix A, concluding that our preference is to base the target fund on the estimated cost of purchasing a single life index-linked annuity, for the following reasons:

- It satisfies the requirements of security and inflation protection, by providing enough money to purchase a guaranteed index-linked income for life;

- It provides a reasonable fund for those wishing to pursue drawdown, where flexibility and legacy needs are more significant considerations, including perhaps some immediate cash requirements.

2.12. We considered a lower target fund, but noted that this would not enable a consumer to fully satisfy the requirements of security and inflation protection, while also not providing enough to enable drawdown with sufficient confidence of the money not running out in retirement.

\footnotetext{
${ }^{12}$ Institute \& Faculty of Actuaries: Define Contribution Participation Accumulation \& Decumulation Working Party - since renamed the Saving for Retirement Working Party (2017) Pension Decumulation Market Research.
} 
2.13. We also considered adopting a higher target fund, which would provide an enhanced ability to meet the various potential objectives listed above, but rejected it because it would significantly increase the calculated cost of pension provision and might be deemed overly prudent.

\section{Target fund}

2.14. As explained above, we have based the target fund at retirement on the cost of purchasing a single life, index-linked annuity using the approach described in Appendix A.

2.15. The target fund will vary according to the consumer's current age, due to projected improvements in mortality. For a consumer currently aged 22, with a SPA of 68,

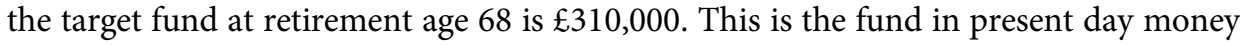
terms and so will increase annually in line with AWE.

\section{Lifetime Pension Contribution (LPC)}

3.1. Having set the target fund, we next need to consider the level of contributions needed to achieve that fund at retirement.

3.2. For our first RoT, we propose the development of the LPC, as being an indicative monthly contribution payable over a full working life to achieve a reasonable level of retirement income. The LPC would be aimed primarily at young consumers, to provide an early directional steer on the long-term cost of pension provision.

3.3. The importance of starting to contribute early is well known (but not necessarily well acted upon). The current $\mathrm{A} / \mathrm{E}$ minimum age is 22 , and that is also the age by when most young people will have entered the workplace and can be realistically expected to start making pension contributions. We therefore based our LPC calculation on contributions commencing at age 22 .

3.4. The LPC is based on a specific RIT and retirement age, which will need widespread debate to determine what is appropriate for these purposes.

3.5. We envisage that the LPC would be updated annually by the rise in AWE, to help stabilise it when expressed as a percentage of a consumer's earnings.

\section{Calculating the $L P C$}

3.6. By way of illustration, we derived the LPC based on what we regard as a reasonable target for an average consumer: a RIT of $£ 18,000$ (about two-thirds of annualised AWE) payable from age 68 , requiring a DC pension of about $£ 9,500$ after allowing for a full State pension. As explained in section 2, this requires a target fund of $£ 310,000$ at age 68 in present day money terms.

3.7. We calculated the LPC using various alternative assumptions, with the results being set out in Tables 1 and 2 and, as explained later, concluded that a single representative LPC

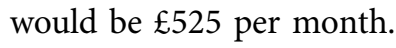

\section{Variation in Assumed Investment Return}

3.8. The great majority of consumers are invested in their scheme's default lifestyle strategy, which for an increasing number of schemes targets drawdown at retirement. This is the approach underpinning our Central assumption, which is set out in Appendix B along with the alternative assumptions referred to below. 
3.9. The Lower and Higher assumptions also target drawdown but with assumed investment returns $0.5 \%$ p.a. lower or higher respectively than the Central assumption.

3.10. The Annuity assumption assumes the same investment return as Central prior to the lifestyle period (the period of de-risking prior to retirement), and then targeting an annuity purchase at retirement.

3.11. We show in Table 1 how the LPC varies under different investment scenarios with assumed real earnings growth of $1.5 \%$ p.a., based on contributions commencing from age 22 .

Table 1. LPC under different investment scenarios, real earnings growth $1.5 \%$ p.a

\begin{tabular}{lcccc}
\hline Investment strategy & Central & Lower & Higher & Annuity \\
\hline LPC, $£$ per month & 510 & 560 & 460 & 545 \\
\hline
\end{tabular}

\section{Variation in Real Earnings Growth Assumption}

3.12. Table 2 shows how the LPC varies according to the real earnings growth assumption.

Table 2. LPC according to different assumed real earnings growth (Central assumptions)

\begin{tabular}{lcccc}
\hline Real earnings growth & $1.0 \%$ & $1.25 \%$ & $1.5 \%$ & $2.0 \%$ \\
\hline LPC, £ per month & 450 & 480 & 510 & 570 \\
\hline
\end{tabular}

\section{Conclusions}

3.13. On the basis of a single LPC being adopted (which has considerable merit for a RoT), we suggest $\mathfrak{E} 525$ as being an approximate average of the Central and Annuity amounts with real earnings growth of $1.5 \%$ p.a. and assuming contributions commence at age 22 , acknowledging that drawdown is a very popular alternative to annuitisation ${ }^{13}$. In addition, $\mathfrak{E} 525$ is broadly equivalent to an average of the various amounts in Tables 1 and 2, which indicates it is representative of the range of alternative assumptions that we have illustrated.

3.14. The assumptions underlying the calculation of the LPC (LPC assumptions), as a blend of the Central and Annuity scenarios, equate to an assumed average real return before retirement of about 2.65\% p.a. as noted in Appendix B. Since we are assuming real earnings growth of $1.5 \%$ p.a., this implies an investment return net of AWE and charges of only $0.4 \%$ p.a., a reflection of the current low interest rates.

3.15. The LPC assumptions were also applied for deriving the other RoTs in this paper.

3.16. $£ 525$ is the monthly equivalent of around $23 \%$ of AWE, and an even higher percentage for a consumer currently earning less than that and who aspires to a RIT of $£ 18,000$. This is clearly a very steep cost, alleviated to the extent that there is an employer to share some of the burden, and of course tax relief.

3.17. Adopting a LPC at that level is likely to disengage consumers, and we consider in section 7 the issues arising regarding affordability.

\footnotetext{
${ }^{13}$ Financial Conduct Authority (2018) Data Bulletin No. 14: Latest trends in the retirement income market.
} 


\section{Some Further Rules of Thumb}

4.1. We next consider how other RoTs might be developed, to assist consumers in their pension planning. Like the LPC, these RoTs are aimed primarily at younger consumers (in their 20s), who have minimal accumulated DC funds so that the level of future contributions is the main consideration.

4.2. Older consumers can still use the RoTs described in this section, as well as the LPC, in conjunction with the benchmark funds discussed in section 5 .

\section{Retiring Later than Age 68}

4.3. If the consumer continues to make DC contributions beyond age 68 and defers drawing State pension until the DC pension commences, Table 3 shows how the required monthly contribution payable from age 22 to retirement reduces:

4.4. This suggests the following RoT:

Table 3. Monthly contribution from age 22 to retirement (shows example LPC at age 68)

\begin{tabular}{lllllll}
\hline Retirement age & 68 & 69 & 70 & 71 & 72 & 73 \\
\hline Monthly contribution, $£$ & 525 & 465 & 405 & 355 & 310 & 265 \\
\hline
\end{tabular}

\section{Rule of thumb: Monthly contribution = LPC less $£ 55$ for each year retirement is delayed after age 68}

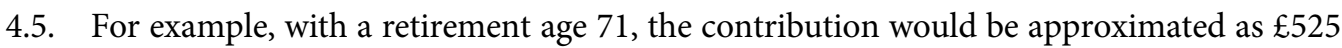

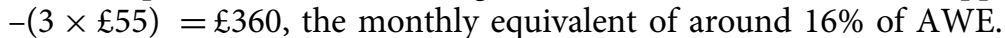

4.6. This is based on the current terms on which State pension is increased when taken late. If the consumer were instead to start drawing State pension at age 68, but continue to make DC contributions and retire later, the RoT for a RIT of $£ 18,000$ would be LPC less $£ 35$ for each year DC retirement is delayed beyond age 68 .

\section{Estimating a Target Pension}

4.7. We derived some further RoTs that do not depend on the LPC, or on any specific RIT. Instead, they can be used to estimate the target pension (exclusive of State pension) based on the current level of contributions, including those paid by the employer.

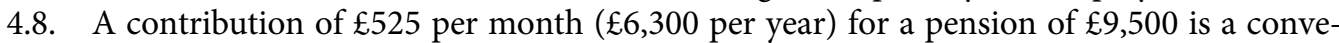
nient ratio of about 1.5. We therefore propose a further RoT based on contributions commencing at age 22 :

\section{Rule of thumb: Target Pension = Annual contribution $\times 1.5$}

4.9. For example, let us assume that a 22 -year-old consumer earning $£ 20,000$ per year is in an automatic enrolment scheme with minimum contributions, which from April 2019 amount to $£ 1,100$, of which the employer pays about $£ 400$. The Target Pension RoT tells us that the consumer is on course for a pension at age 68 of $£ 1,100 \times 1.5$, or about $£ 1,600$. If we add a full State pension of about $£ 8,500$, this gives a prospective pension of around $£ 10,100$. 
4.10. The consumer could use the same RoT to estimate the impact of an increase in contribution. For example, a further $5 \%$ of earnings amounts to $£ 1,000$, thereby increasing the target pension by $£ 1,500$ to about $£ 11,600$.

4.11. The target pension RoT can be extended for other retirement ages. Appendix D shows the annual contribution required per $£ 1,000$ of pension, and the ratio of pension: contribution.

4.12. The target pension ratio of 1.5 can be seen for retirement age 68 . The ratio at other ages is also shown in Table 4 (we have assumed the consumer continues to work and contribute until the retirement age).

Table 4. Ratio of target pension to annual contribution by retirement age

\begin{tabular}{llllllll}
\hline Retirement age & 60 & 65 & 68 & 69 & 70 & 71 & 72 \\
\hline Ratio & 0.8 & 1.2 & 1.5 & 1.6 & 1.7 & 1.9 & 2.0 \\
\hline
\end{tabular}

4.13. The earlier example showed a target pension of $£ 11,600$ at age 68 , after the consumer contributed an additional $5 \%$ of earnings. This included a State pension of about $£ 8,500$,

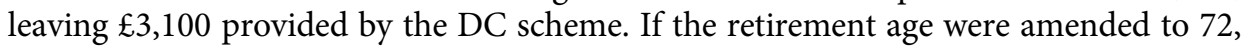

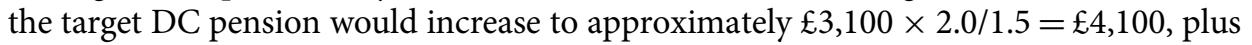
the State pension which would have a late retirement increase applied if also deferred until age 72 .

4.14. For retirement before SPA, additional contributions will be required if the consumer wishes to provide for a temporary pension equivalent to the amount of State pension for the period prior to SPA.

\section{Issues for Older Consumers}

5.1. Young consumers are relatively straightforward since future contributions are the main consideration. For an older consumer, there is the important further consideration of the accumulated DC funds built up in the past, which is where benchmark funds can play a role.

\section{Benchmark Funds}

5.2. An older consumer can use the same RoTs described in sections 3 and 4, provided they also check if they are "on track" according to the size of DC fund anticipated at any given age (the "benchmark fund"). Chart 1 shows the benchmark funds assuming contributions commence from age 22 , to provide a target pension of $£ 1,000$ from age 68 . The target pension RoT tells us that the required annual contributions will be $£ 1,000$ / $1.5=\mathfrak{E} 666$. The benchmark fund at any specific age would increase annually in line with AWE, in the same way as the LPC.

5.3. Inspection of the benchmark funds reveals the potential RoT shown in Table 5. With an assumed "real" investment return of only $0.4 \%$ p.a. (see section 3.14 ), the impact of investment growth is negligible up to age 40 and can therefore be ignored, as revealed by the formula below (noting we have assumed contributions commence at age 22). At later ages, the impact of investment growth remains modest and is accounted for by applying a lower deduction to the consumer's age. 
Table 5. Benchmark fund rule of thumb for contributions commencing at age 22

\begin{tabular}{lc}
\hline Age & Multiple of annual contribution \\
\hline Up to 40 & Age -22 \\
\hline 41 to 50 & Age -20 \\
\hline 51 or more & Age -18 \\
\hline
\end{tabular}

Benchmark fund age 22 to 68 (in real terms relative to AWE)

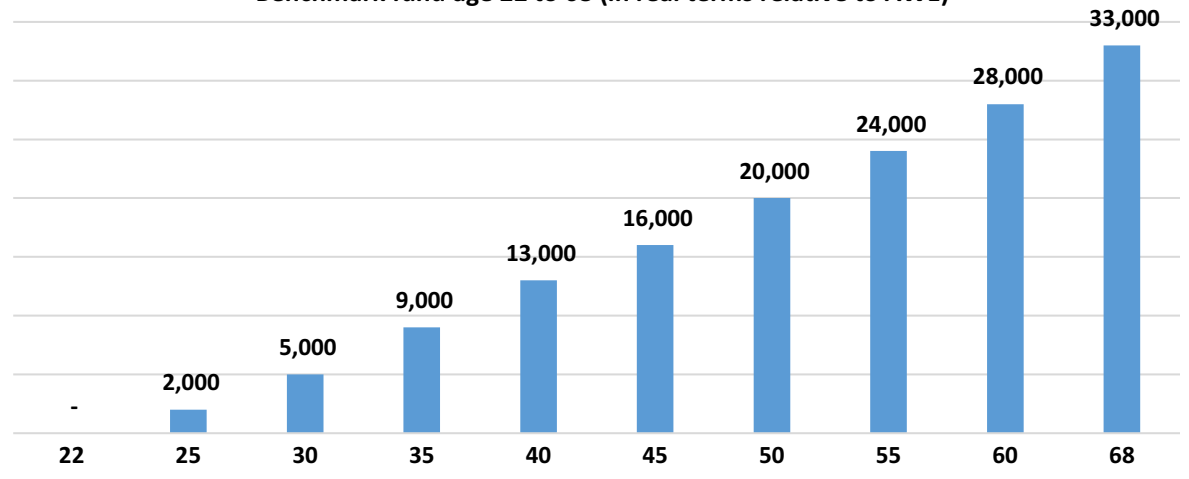

Chart 1. Benchmark fund for pension of $£ 1,000$ at age 68 .

5.4. For example, referring to Chart 1, we expect a fund at age 45 of about $£ 666 \times(45-20)=£ 16,600$ (compared with $£ 16,000$ in the Chart).

5.5. Let us suppose that a consumer aged 45 is contributing $£ 2,000$ per year, aiming for a target pension at age 68 of $£ 2,000 \times 1.5=£ 3,000$. The benchmark fund is

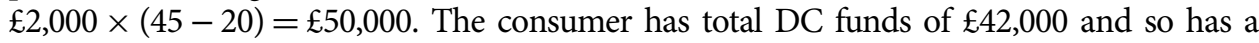
shortfall of $£ 8,000$; this can be funded over a period of time in addition to continuing the annual contributions of $£ 2,000$. In practice, all these figures would be adjusted for increases in AWE.

5.6. The same consumer contributing our illustrative LPC of $£ 525$ per month, to provide a RIT at age 68 of $£ 18,000$ including State pension, would expect to have a fund at age 45 of

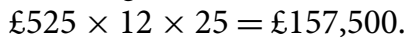

5.7. Implementing a Pensions Dashboard will be very important in enabling people to quickly establish their total DC savings in order to assess these relative to the benchmark funds. Indeed, one idea would be to show a benchmark fund on the Dashboard.

\section{Variation in Earnings Growth}

5.8. We have assumed that a consumer's contributions and target pension will increase in line with AWE, so what are the implications if that were not the case in practice?

5.9. If the consumer's earnings grow by more or less than AWE, then that will cause a divergence from the benchmark fund, which will be revealed when a check is made. It is possible that the consumer may wish to adjust the target pension though, to reflect lower (or higher) aspirations arising from the current level of earnings. 


\section{Consumers Closer to Retirement}

5.10. On nearing retirement, it becomes increasingly important to adopt a personalised approach, taking into account individual circumstances. So what are the implications of such people using the RoTs?

5.11. If we assume that life expectancy will continue to increase over time, then older consumers have lower life expectancies than their younger counterparts and hence lower benchmark funds (and correspondingly lower contribution requirements). This is illustrated in Chart 2 for a target pension of $£ 1,000$ per year from age 68 , which compares the benchmark fund at each age for a consumer who has reached that age in 2018 versus a consumer who is aged 22 in 2018.

Benchmark fund for $£ 1,000$ pension at 68

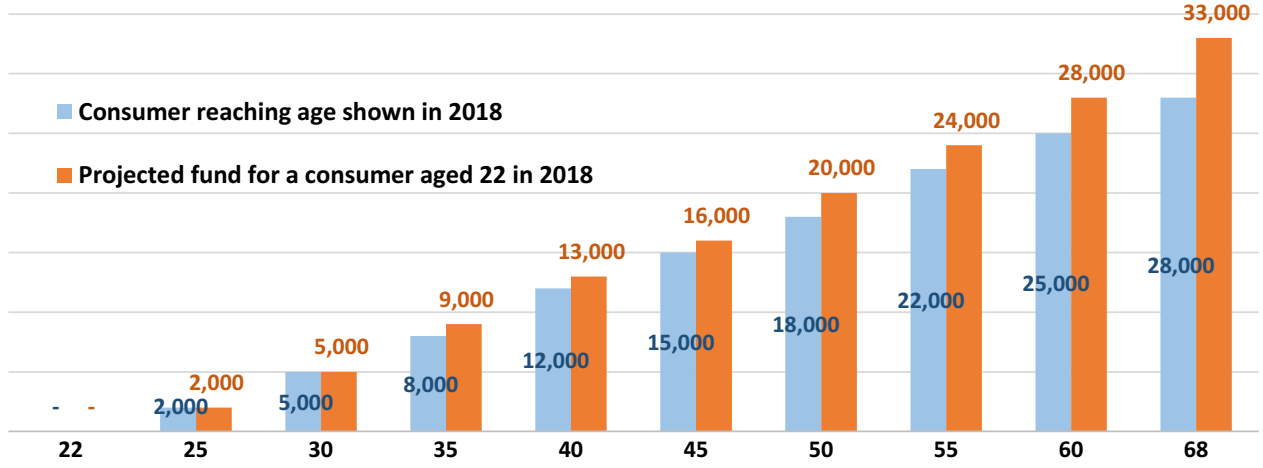

Chart 2. Benchmark fund - generational impact.

5.12. It can be observed that the difference is modest up to age 45 , and then the figures start to diverge. For consumers older than 45 who do use the RoTs, the calculated costs will be overstated.

5.13. This in itself may not be deemed a bad thing, but nevertheless it will be important when communicating the RoTs to emphasise that for consumers approaching retirement it is important to have regard for individual circumstances.

\section{Variation in Contributions}

6.1. Our RoTs have been developed assuming that consumers will contribute a fixed percentage of earnings throughout their working lifetime (assumed from age 22) and use the benchmark funds to check if they are "on track" to meet their retirement objectives, making adjustments accordingly. In this section, we explore further how contributions may vary over time.

\section{Non-Uniform Contribution Patterns}

6.2. It is likely that a significant number of consumers will not contribute a uniform percentage of earnings. For example, some may prefer to pay lower contributions in the early years, perhaps to save for a property purchase or to leave enough income to bring up a family, increasing their contributions in later years when it becomes more affordable.

6.3. Our RoTs can still be applied in such circumstances, since the benchmark funds will indicate the extent of the shortfall and thereby provide a guide to the additional contributions needed in later years. A similar approach can be used by someone who has had a career break, e.g. to care for a young family or elderly relative. 
6.4. Table 6 illustrates the importance of starting to contribute early. While we could derive a RoT from these results, it would be inconsistent with the rest of our RoTs which are internally consistent based on contributions commencing at age 22. Also, because of $\mathrm{A} / \mathrm{E}$ it is unlikely that consumers would make no contributions from age 22 , although the level of contributions may be relatively low.

Table 6. Required monthly contribution according to different starting ages. Using life expectancy for age contributions commenced

\begin{tabular}{lcccc}
\hline Contributions start age & 22 & 25 & 28 & 30 \\
\hline Monthly contribution, $£$ & 525 & 555 & 595 & 625 \\
\hline
\end{tabular}

\section{Adjusting Contributions to Reflect Investment Experience}

6.5. Taking some investment risk is necessary to make saving for retirement affordable, but that requires contributions to be reviewed and adjusted as necessary, in order to stay on track to achieve a given retirement pension.

6.6. Chart 3, showing net income by age, illustrates what happens if contributions are not adjusted to reflect investment experience. Stochastic projections have been used, ${ }^{14}$ and the chart shows the median and percentile outcomes. All figures are expressed in present day money terms.

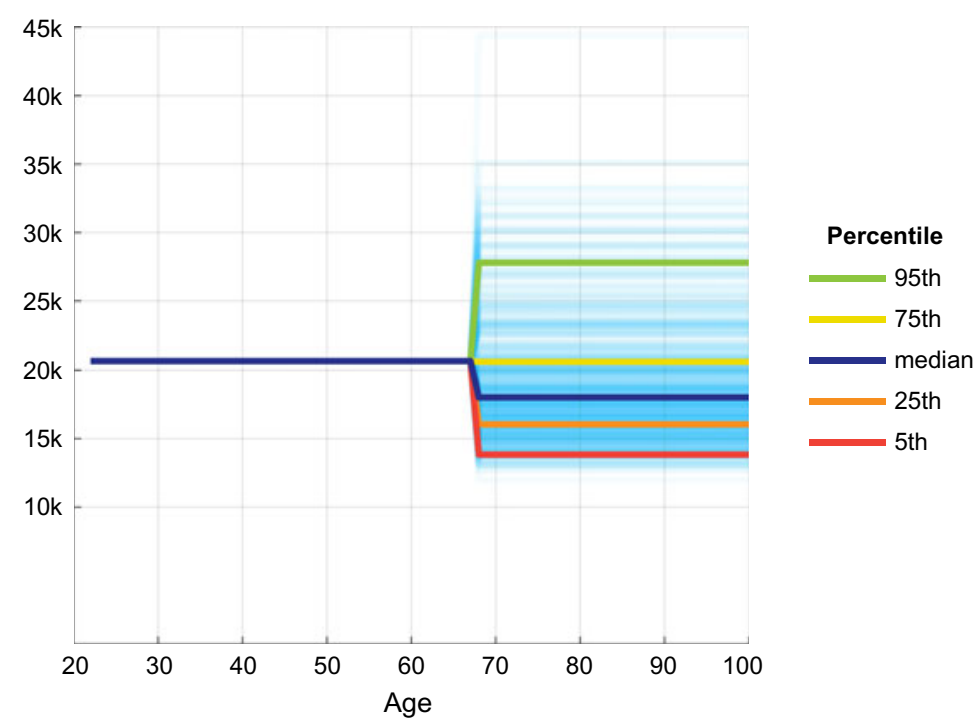

Chart 3. Contributions a constant $\%$ of earnings from age 22 to 68 . Target pension $£ 18,000$.

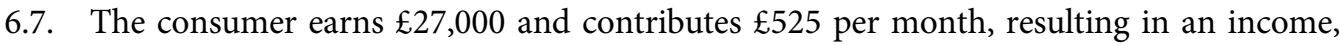
net of pension contribution but before tax, of almost $£ 21,000$ for the whole period from age 22 to 68 . The target pension at age 68 is $£ 18,000$, which is assumed to be secured with

\footnotetext{
${ }^{14}$ Charts 3 and 4 are outputs from stochastic modelling using Financial Canvas by Sciurus Analytics (see Appendix C for more detail).
} 


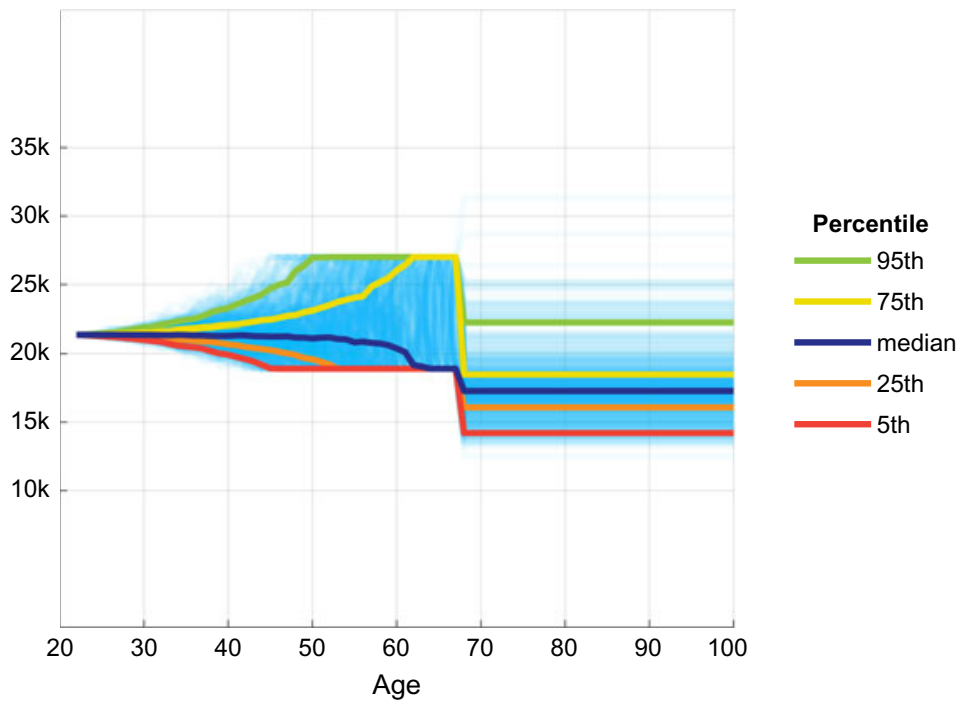

Chart 4. Same as Chart 3, but contributions adjusted annually (cap of 30\% earnings).

an annuity and thereby be constant in retirement. While the median pension from age 68

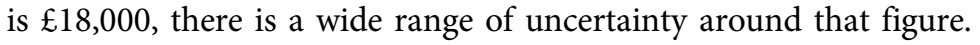

6.8. Chart 4 is based on the same situation, but where contributions are adjusted annually to reflect investment experience, capped at an illustrative 30\% of earnings (results for a lower cap will be intermediate between Charts 3 and 4). The level of uncertainty in retirement income is greatly reduced, but at the expense of an uncertain and volatile preretirement income.

6.9. This illustrates the trade-off between pre- and post-retirement uncertainty. In fact, further analysis, which is not presented in this report, shows that removing all postretirement uncertainty is not even achieved if the consumer could afford to contribute $100 \%$ of earnings where necessary.

\section{Further Comments}

6.10. In practice, the consumer could alleviate any financial pressures pre-retirement by lowering the target retirement income or increasing the planned retirement age.

6.11. The entire period before and after retirement can be viewed as a continuum, with the consumer seeking to smooth consumption, while avoiding surprises and periods of relative poverty. We suggest that further work should be undertaken using the above type of analysis to explore the trade-offs involved, which could lead to the development of further RoTs for both the pre- and post-retirement periods.

\section{A Question of Affordability}

7.1. We derived a LPC of $£ 525$ per month in section 3, noting that this is unlikely to be affordable for many people as it equates to about $23 \%$ of annualised AWE. In this section, we explore the issues arising. 


\section{Automatic Enrolment}

7.2. The minimum employer contribution under automatic enrolment (A/E) is $3 \%$ from April 2019. A phased increase in employer contribution to $6 \%$ (with total contributions rising to $12 \%$ ), as proposed by the PLSA ${ }^{5}$, would provide some assistance in making DC pension provision more affordable for consumers.

7.3. We also support the Government's proposal to remove the lower earnings threshold when calculating qualifying earnings.

7.4. Widening the scope of A/E to include the self-employed should also be a priority.

7.5. A/E was never intended to provide sufficient contributions to achieve an adequate pen$\operatorname{sion}^{11}$, and voluntary contributions were envisaged to make up the shortfall. This would remain the case if our illustrative LPC of $£ 525$ per month were adopted.

\section{Retirement Age}

7.6. Contributing longer and retiring later would clearly make retirement more affordable. For example, using the RoT from section 4.7, the LPC for a RIT of $£ 18,000$ from age

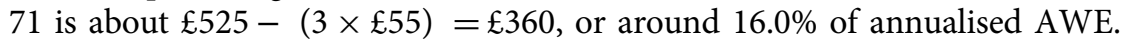

\section{Choice of Target Pension Benefit}

7.7. The amount of the LPC is very sensitive to the choice of RIT on which it is based, as illustrated in Table 7.

Table 7. LPC for various choices of RIT

\begin{tabular}{lccc}
\hline RIT & RIT as \% of annualised AWE & LPC (per month) & $\begin{array}{c}\text { LPC as \% of monthly } \\
\text { equivalent of AWE }\end{array}$ \\
\hline$£ 18,000$ & $67 \%$ & 525 & $23.3 \%$ \\
\hline$£ 17,000$ & $63 \%$ & 470 & $20.8 \%$ \\
\hline$£ 16,000$ & $59 \%$ & 415 & $18.3 \%$ \\
\hline
\end{tabular}

7.8. Further debate will be needed to determine an appropriate choice, and the PLSA's proposed RITs (not available at the time this paper was finalised) can contribute to such a discussion.

7.9. One consideration is that retirement expenditure is determined by household rather than individual, and there is plenty of evidence to suggest that a couple's retirement expenditure is significantly less than twice that of a single pensioner. How that might translate into the choice of RIT for determining the LPC merits further analysis.

7.10. We believe the LPC should be based on an appropriate choice of RIT, and that if the result is considered unaffordable for general use, then consumers must expect to work longer and retire later in order to achieve an adequate retirement income.

\section{More Efficient Decumulation Market}

7.11. Part of the problem with affordability lies in the inefficiencies of the individual DC market. We therefore suggest there is a need to find ways to harness bulk purchasing powers, along with the benefits of pooling investment and mortality risks. This would make DC pension provision more affordable and predictable for the consumer. The 
growth of master trusts should lend itself to the development of such solutions, as would the introduction of collective DC schemes.

7.12. One aspect of particular concern is that the cost of individually purchased annuities is currently around 15-20\% higher than the terms typically available to defined benefit pension schemes for bulk purchase under a buy-in or buy-out. This factor alone might reduce our calculated LPC down to around $£ 430$ per month, or the monthly equivalent of around $19.0 \%$ of AWE.

\section{Low Interest Rates}

7.13. Low interest rates are a major reason for the current high cost of pension provision, and that is reflected in our RoT that the target pension at age 68 is 1.5 times the annual contribution. The impact of an increase in interest rates will depend on the timing of the increase and how it affects the investments, but as a rough indication an increase in long-term interest rates to $4 \%$ p.a. from the current (March 2019) level of around 2\% p.a. might reduce the LPC by around $30 \%$.

7.14. Clearly nobody can predict the future level of interest rates, especially when we are looking ahead for 40 years or more. Many commentators believe we are in a new "norm" of low interest rates, so we should not rely on a reversion to the high rates experienced in the past.

7.15. It should be noted though that we are still experiencing the effects of an unprecedented level of QE following the 2008 global financial crisis. Anticipating a modest rise in longterm interest rates on account of the unravelling of QE could be deemed reasonable when we are predicting what may happen in 40 years' time and would have a significant impact.

\section{Conclusions}

7.16. The issue of affordability is a serious one and requires widespread discussion. We believe the concept of the LPC can provide a useful platform for promoting such a debate, having regard to the various issues outlined in this section.

\section{Rules of Thumb in Practice}

8.1. We have developed a number of RoTs in this paper, which are summarised in Table 8. We conclude by discussing how these RoTs might be put into practice.

Table 8. Rules of thumb in summary

\begin{tabular}{|c|c|}
\hline Rule of thumb & Description \\
\hline $\begin{array}{l}\text { Lifetime Pension } \\
\text { Contribution) (LPC) }\end{array}$ & $\begin{array}{l}\text { Monthly contribution over a full working life to achieve a reasonable retirement } \\
\text { income. Our illustrative LPC is } £ 525 \text { (the monthly equivalent of around } 23 \% \text { of AWE), } \\
\text { based on a target income at age } 68 \text { of } £ 18,000 \text { inclusive of a full State pension, with } \\
\text { contributions and target pension assumed to increase each year by AWE. }\end{array}$ \\
\hline Later Retirement & $\begin{array}{l}\text { Monthly contribution required to achieve the same retirement income as the LPC but } \\
\text { for a later retirement age (for both State and DC pensions). For a LPC of } £ 525 \text {, it is } \\
\text { calculated as the LPC less } £ 55 \text { for each year between } 68 \text { and retirement age }\end{array}$ \\
\hline Target Pension at age 68 & $\begin{array}{l}\text { Target pension at age } 68=\text { annual contribution } \times 1.5 \text {, where annual contribution is } \\
\text { calculated over a full working life (from age } 22 \text { ) }\end{array}$ \\
\hline $\begin{array}{l}\text { Target pension at other } \\
\text { ages }\end{array}$ & $\begin{array}{l}\text { The multiple ( } 1.5 \text { at age } 68 \text { ) varies according to retirement age. For example, target } \\
\text { pension at age } 70=\text { annual contribution } \times 1.7 \text {, where annual contribution is } \\
\text { calculated over a full working life (from age } 22 \text { ). }\end{array}$ \\
\hline Benchmark fund & $\begin{array}{l}\text { Benchmark fund is annual contribution } \times(\text { age }-n) \text {, where } n=22 \text { (for ages up to } 40 \text { ), } \\
n=20 \text { (for ages } 41-50) \text { and } n=18 \text { (for ages } 51 \text { or more). This is closely related to the } \\
\text { development of the Pensions Dashboard. }\end{array}$ \\
\hline
\end{tabular}


8.2. We see merit in developing a single LPC, in order to create the maximum impact. Aimed primarily at young consumers, it would provide an early indication of the contribution needed for a reasonable retirement income, which can be refined at a later date once retirement plans start to emerge. Older consumers will wish to adopt a more tailored approach, but the LPC can still serve as a prompt if their contributions are below that level.

8.3. The LPC would act as a benchmark of pension cost, increasing annually in line with AWE and adjusted periodically for other factors, such as interest rate changes.

8.4. Promoting the LPC in the national media would help cement it in the general psyche.

8.5. As discussed in section 7 , the initial level of the LPC would need widespread debate to ensure it is appropriate and was not set at a level regarded as unrealistic by consumers or the financial press.

\section{Potential Smartphone App}

8.6. While the LPC is a simple concept, the other RoTs we have developed involve some calculations. These calculations lend themselves to automation, e.g. via a smartphone app. Consumer acceptance of this app might be enhanced if it were developed and endorsed by an independent body.

8.7. We appreciate that there are already many tools available to guide consumers with their retirement savings, and which offer a more tailored approach. The app we propose would aim to complement these tools, and in many cases would hopefully enthuse consumers to take a more personalised approach through one of these other tools.

\section{Nudges}

8.8. RoTs will be more effective if used in conjunction with "nudges", i.e. promoting actions at key "teachable" moments. An example is auto-escalation, where typically the percentage of earnings contributed increases automatically over time.

\section{Market Research}

8.9. RoTs have the potential to influence general behaviour of both consumers and employers through clear and simple messages.

8.10. We suggest that market research is undertaken to test whether the RoTs, including the LPC, would be helpful. The research can also address the means of communicating the RoTs, including the idea of a smartphone app.

Acknowledgements. The authors are extremely grateful for the contribution made to this paper by Chris Squirrell and Eddy Barnard of Sciurus Analytics. They have given a lot of their time to critique and provide input to our approach and to develop a model using their Financial Canvas software that formed the basis of much of section 6 .

\section{Appendix A. Approach to Determining Target Fund at Retirement}

A.1. In determining the target fund at retirement, we need to consider the extent to which the consumer wishes to prioritise the following competing objectives:

(a) The target income will continue for life (security);

(b) The target income is protected against the impact of inflation (inflation protection);

(c) Value for money is achieved in the event of early death, or that specific legacy intentions are met (legacy needs);

(d) There is flexibility to vary the income to suit changing circumstances (flexibility); 
(e) Whether the consumer has additional requirements at retirement, such as to pay off debt or finance a holiday or another major discretionary purchase (cash needs).

A.2. Can we choose a single measure of target fund at retirement that represents a fair balance of the above objectives (noting that objectives may be unclear for young consumers and can change over time)? If we could, this would facilitate the development of RoTs.

\section{Cost of an Index-Linked Annuity}

A.3. Since a pension represents an income for life, we start by considering the purchase of a single life, index-linked annuity focussed on fully satisfying the objectives of security and inflation protection.

A.4. We assumed that the terms on which annuities can be purchased are those specified in the Financial Reporting Council's AS TM1 ${ }^{15}$ (TM1) for the purpose of preparing Statutory Money Purchase Illustrations (SMPIs). This approach has the advantages of being consistent with the SMPIs consumers receive each year and being provided by an independent, widely used source, and approximates to the current terms typically available for purchasing individual annuities. The assumptions were as follows:

- An interest rate equal to $50 \%$ of the sum of the FTSE Actuaries' Government Securities Index-Linked Real Yields over 5 years assuming $5 \%$ and $0 \%$ inflation, less $0.5 \%$;

- Mortality based on the year of birth rate derived in equal parts from the tables PMA08 and PFA08 with projected mortality improvements using the CMI model 2 years prior to the calculation date and subject to a $1.25 \%$ p.a. long-term level of improvements;

- A $4 \%$ loading for expenses.

A.5. TM1 specifies that the interest rate to use in the financial year commencing 6 April is that as at the immediately preceding 15 February in that year, which for the $2018 / 19$ financial year is $-2.0 \%$ after the $0.5 \%$ deduction. In practice, it may be appropriate to adopt the same date that the RITs are uprated, in the event that takes place annually.

A.6. Using the sample consumer described in section 2 and TM1 assumptions, the cost of purchasing a single life, index-linked annuity of $£ 9,500$ p.a. at age 68 is $£ 310,000$.

A.7. Following the introduction of pension freedoms in 2015, not many people are buying annuities and they more commonly choose drawdown instead, mainly for the objectives of flexibility and legacy intentions (given that any residual monies in drawdown are payable on death).

A.8. We have carried out some stochastic modelling to illustrate the potential range of outcomes using drawdown, starting with a fund of $£ 310,000$. The results are shown in Table A1, and Appendix C explains the approach we adopted.

Table A1. Drawdown - illustrative range of outcomes: initial fund of $£ 310,000$. Expected years to death are 25 using the assumptions adopted

\begin{tabular}{|c|c|c|c|}
\hline Years retired & Probability drawdown lasts & $\begin{array}{l}\text { Lifetime income that can be supported, } \\
\text { inclusive of the State pension }\end{array}$ & \\
\hline 20 & $100 \%$ & Median income & $£ 17,500$ \\
\hline 25 & $98 \%$ & Range with a $90 \%$ degree of confidence & $£ 14,400$ to $£ 20,400$ \\
\hline 30 & $85 \%$ & & \\
\hline 35 & $66 \%$ & & \\
\hline 40 & $44 \%$ & & \\
\hline
\end{tabular}

A.9. Over a 30 -year period, in $85 \%$ of our 1,000 simulations the drawdown fund did not run out, which is not far short of the $90 \%$ threshold that is commonly viewed as "safe" over that period, although over longer periods than 30 years, the chance of running out of money increases very significantly. Viewed from another perspective, the calculated median lifetime income of $£ 17,500$ is modestly less than the RIT of $£ 18,000$, but there is a significant range of uncertainty with potential to under- or over-shoot the RIT. We have calculated that the range of lifetime income that can be supported with a $90 \%$ degree of confidence is $£ 14,400$ to $£ 20,400$.

\footnotetext{
${ }^{15}$ Financial Reporting Council (2016) AS TM1: Statutory Money Purchase Illustrations Version 4.2.
} 
A.10. However, compared with a single-life annuity, drawdown offers flexibility and value on early death and significant upside potential (not guaranteed of course), while anyone wanting a secure lifetime income can buy an annuity instead with the same fund.

A.11. There are various possibilities for partial or delayed annuitisation. For example, those who buy annuities tend to prefer level ones because they provide a higher initial income, are better priced (reflecting the high cost of insuring the inflation risk), and they could then manage the inflation risk using drawdown.

A.12. Any such variant will have characteristics somewhere between the annuity and pure drawdown, and so similar considerations will apply as discussed above. We therefore conclude that the index-linked annuity approach is reasonable, but are there other options?

\section{Drawdown Based on a Lower Fund}

A.13. Since annuities are generally perceived as being expensive, it is natural to anticipate that a target fund less than the cost of an index-linked annuity is needed when drawdown is considered. The analysis in Table A1 demonstrates the potential for significantly higher income than from an annuity, but there is downside risk.

A.14. A lower fund than $£ 310,000$ would increase the downside risk further, while it would no longer provide enough money to purchase an annuity. We do not consider this to be suitable for our purposes when adopting a single measure of target fund.

\section{Higher Fund than Cost of Index-Linked Annuity}

A.15. A target fund higher than the index-linked annuity approach might serve several purposes:

- If purchasing an annuity, in providing extra monies to purchase capital protection or a dependants' pension on death;

- If pursuing drawdown, by reducing the chance of running out of money;

- Providing extra monies for immediate purposes, i.e. to satisfy objective (e).

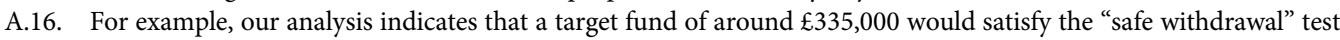
( $90 \%$ chance of the money lasting for 30 years). This corresponds to an initial withdrawal rate of $£ 9,500$ /

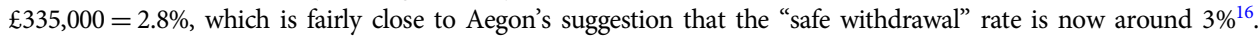
It is also broadly consistent with findings from research carried out by the IFoA ${ }^{17}$ indicating a safe withdrawal rate of $3.5 \%$ to generate a fixed income (noting the rate for an index-linked income will be lower).

A.17. Alternatively, the additional $£ 25,000$ would be approximately sufficient to provide a guarantee that the pension payments will continue for a 20 -year period (which as noted in Table A1 is about $80 \%$ of the period until the expected age at death).

A.18. A third option is that the extra $£ 25,000$ could be used to pay off debt or for significant discretionary expenditure. This would be about $30 \%$ of the maximum tax-free cash sum available from a fund of $£ 335,000$.

A.19. For these reasons, we see this higher target as a viable alternative. It will result in higher contributions and target funds than the index-linked annuity approach, which might be deemed useful in encouraging more savings, although that introduces the risk of making the contribution rates appear too high and thereby disengaging consumers. On balance, we conclude that this method is less preferable than the index-linked annuity approach.

\section{Appendix B. Assumptions Adopted for the Accumulation Phase}

B.1. We have referenced the FCA's prescribed maximum rates of return that financial services companies must use in their calculations when providing retail customers with projections of future benefits ${ }^{18}$.

\section{Earnings Growth}

B.2. The FCA recommend an assumed growth in earnings in excess of Consumer Price Index (CPI) of $1.5 \%$ p.a. to $2.0 \%$ p.a. in the long-term, reducing to $1.25 \%$ p.a. over the next $10-15$ years. We have adopted an assumption of $1.5 \%$ p.a.; the bottom of the recommended long-term range in recognition of the shorter-term advice.

\footnotetext{
${ }^{16}$ Aegon (2017) What's the new sustainable income rate in retirement?

${ }^{17}$ Institute \& Faculty of Actuaries (2018) Can we help consumers avoid running out of money in retirement?

${ }^{18}$ Financial Conduct Authority (2017) Rates of Return for FCA Prescribed Projections.
} 


\section{Investment Returns During Accumulation: Prior to Lifestyle Period}

B.3. We have followed the principles of $\mathrm{TM} 1^{15}$ when setting the assumed investment return, where Appendix C, paragraph C.2.3 states, "In determining the accumulation rate the provider must take account of the expected returns from the current and anticipated future investment strategy of the member's funds over the period to the retirement date".

B.4. Most consumers are invested in their scheme's default lifestyle investment strategy, and we have used that as a basis for setting our assumptions, assuming a 10-year lifestyle period which is fairly representative of the market.

B.5. The FCAs recommended investment returns are shown in Table B1.

B.6. The modern investment portfolio typically contains a wide range of growth-seeking assets in addition to equities, and a typical medium risk diversified investment portfolio will target an investment return before charges of around $3.0 \%$ p.a. above CPI. We adopted this as our central assumption and included two variants as per Table B2.

B.7. The absolute returns assume inflation of $2.5 \%$ p.a. which is the assumption used in the FCA's analysis and also that prescribed by TM1.

Table B1. FCA assumed real investment returns by asset class

\begin{tabular}{lcc}
\hline Asset class & Range & Mid-point \\
\hline Equities & $3.0-5.0 \%$ & $4.0 \%$ \\
\hline Property & $2.5-3.5 \%$ & $3.0 \%$ \\
\hline Corporate bonds & $0.1-0.5 \%$ & $0.3 \%$ \\
\hline Government bonds & $-1.0-0.0 \%$ & $-0.5 \%$ \\
\hline Cash & $-1.5-0.5 \%$ & $-1.0 \%$ \\
\hline
\end{tabular}

Table B2. Assumed real investment returns prior to lifestyle period

\begin{tabular}{lcc}
\hline & Real return & Absolute return \\
\hline Low & $2.5 \%$ & $5.0 \%$ \\
\hline Intermediate & $3.0 \%$ & $5.5 \%$ \\
\hline High & $3.5 \%$ & $6.0 \%$ \\
\hline
\end{tabular}

\section{Investment Returns During Accumulation: Lifestyle Period}

B.8. For lifestyling that targets drawdown, we assumed a target investment strategy at retirement providing a real return of $1.75 \%$ p.a.

B.9. For lifestyling that targets annuity purchase, we assumed a target investment strategy at retirement providing a real return of $-1.0 \%$ p.a. with an accelerated level of de-risking in the final 5 years.

B.10. We made no specific allowance for a lifestyle strategy targeting cash; in practice, we expect any transition into cash to take place close to retirement and will not therefore materially impact the investment returns.

\section{Investment Returns in Accumulation Phase (Summary)}

B.11. Table B3 summarises our assumptions, all before allowance for expenses. Transitions in the lifestyle period are assumed to be linear.

B.12. The LPC assumptions are a blend of the Central and Annuity scenarios and are roughly equivalent to assuming a uniform real return of $2.65 \%$ p.a. over the period from age 22 to 68 . These assumptions were used to derive the LPC and the other RoTs in this paper.

B.13. We have assumed an annual management charge (AMC) of $0.75 \%$ p.a. to cover investment and administration costs, which is the current cap on the default lifestyle strategy for A/E purposes of $0.75 \%$. 
Table B3. Investment scenarios pre-retirement

\begin{tabular}{|c|c|c|c|}
\hline \multirow[b]{2}{*}{ Scenario } & \multicolumn{2}{|c|}{ Real return p.a. before expenses } & \multirow[b]{2}{*}{ Target at retirement } \\
\hline & Pre-lifestyle period & Lifestyle period & \\
\hline Central & $3.0 \%$ & $3.0 \%$ reducing to $1.75 \%$ at retirement & Drawdown \\
\hline Lower & $2.5 \%$ & $2.5 \%$ reducing to $1.75 \%$ at retirement & Drawdown \\
\hline Higher & $3.5 \%$ & $3.5 \%$ reducing to $1.75 \%$ at retirement & Drawdown \\
\hline Annuity & $3.0 \%$ & $\begin{array}{l}3.0 \% \text { reducing to } 2.0 \% \text { over } 5 \text { years, then } \\
\text { to }-1.0 \% \text { over a further } 5 \text { years }\end{array}$ & Annuity purchase \\
\hline LPC & $3.0 \%$ & $3.0 \%$ reducing to $1.0 \%$ at retirement & Blend \\
\hline
\end{tabular}

\section{Appendix C. Stochastic Modelling Drawdown Modelling in Appendix A}

C.1. In order to illustrate the risk implicit in drawdown, we carried out stochastic modelling. We used a statistical model that required only the mean and standard deviation (or volatility) of the assumed investment return and carried out 1,000 simulations to derive the assumed spread of outcomes. The model we used was the Laplace (double exponential) distribution, which has been suggested ${ }^{19}$ to fairly accurately depict historical stock market returns. It is symmetrical and similar to the Normal distribution, but has a taller, more pointed centre and fatter tails.

C.2. We assumed a mean real investment return of $1.75 \%$ p.a. as described in Appendix B, on the assumption that none of the retirement fund is held in cash. We further assumed after 10 years of retirement a modest reduction over 5 years to a real return of $1.25 \%$ p.a. This is before deducting an assumed $0.75 \%$ p.a. for expenses. We assumed a volatility of $7.0 \%$ as being representative of a typical investment strategy having a mean real return of $1.75 \%$ p.a. reducing to a volatility of $6 \%$ p.a. for a return of $1.25 \%$ p.a.

C.3. We assumed inflation of 2.5\% p.a., as per both TM1 and the FCA assumptions mentioned in Appendix B.

C.4. In addition to showing the proportion of the 1,000 simulations where the money ran out after various periods, we also showed the income that can be supported until the age when, according to the corresponding deterministic projection, the fund first runs out. This was derived for each simulation by reference to the residual fund (positive or negative) at that age, and then deriving the income that would have achieved a zero fund instead.

\section{Impact of Investment Experience in section 6}

C.5. The stochastic projections carried out in the period before retirement were made using assumptions consistent with the drawdown analysis.

C.6. The investment returns were simulated using the Central assumptions described in Appendix B, with volatility consistent with the assumptions in C.1 and C.2 above.

C.7. We have assumed that the cost of purchasing an annuity at retirement is fixed in real terms. Whilst this is clearly an unrealistic assumption in isolation, we believe that the assumptions in aggregate are reasonable for the purposes of our simplified examples and that the insights into the broad range of retirement outcomes are valid.

C.8. Further insights into the control mechanisms available to DC savers would be gained by introducing uncertainty to the prices of the annuity along with assumptions for how these relate to the investment performance of the accumulation funds. This can be explored in any subsequent work.

\section{Appendix D. Variation in Cost of Pension by Retirement Age}

D.1. Table D1 shows how the required contributions and benchmark funds vary according to retirement age, based on a target pension of $£ 1,000$ per year.

D.2. For example, the required annual contribution from age 22 for retirement at age 68 is $£ 666$, so the ratio of target pension: annual contribution is 1.5 .

\footnotetext{
${ }^{19}$ Harwood (2017) Predicting Stock Market Returns - Lose the Normal and Switch to Laplace : Six Figure Investing.
} 
Table D1. Benchmark fund and annual contributions for $£ 1,000$ p.a. pension on retiring at various ages, for a consumer aged 22 years and commencing contributions at that age

\begin{tabular}{|c|c|c|c|c|c|c|c|c|c|c|c|c|c|}
\hline \multirow[b]{2}{*}{ Fund at age shown (£000's) } & \multicolumn{13}{|c|}{ Retirement age } \\
\hline & 60 & 61 & 62 & 63 & 64 & 65 & 66 & 67 & 68 & 69 & 70 & 71 & 72 \\
\hline 22 & - & - & - & - & - & - & - & - & - & - & - & - & - \\
\hline 25 & 3 & 3 & 3 & 3 & 3 & 2 & 2 & 2 & 2 & 2 & 2 & 2 & 1 \\
\hline 30 & 9 & 9 & 8 & 8 & 7 & 7 & 6 & 6 & 5 & 5 & 5 & 4 & 4 \\
\hline 35 & 16 & 15 & 14 & 13 & 12 & 11 & 10 & 10 & 9 & 8 & 8 & 7 & 7 \\
\hline 40 & 22 & 21 & 19 & 18 & 17 & 16 & 14 & 13 & 13 & 12 & 11 & 10 & 9 \\
\hline 45 & 29 & 27 & 25 & 23 & 22 & 20 & 19 & 18 & 16 & 15 & 14 & 13 & 12 \\
\hline 50 & 36 & 33 & 31 & 29 & 27 & 25 & 23 & 22 & 20 & 19 & 17 & 16 & 15 \\
\hline 55 & 42 & 39 & 37 & 35 & 32 & 30 & 28 & 26 & 24 & 23 & 21 & 19 & 18 \\
\hline 60 & 46 & 44 & 42 & 39 & 37 & 35 & 33 & 30 & 28 & 26 & 25 & 23 & 21 \\
\hline Retirement & 46 & 45 & 43 & 41 & 39 & 38 & 36 & 34 & 33 & 31 & 30 & 28 & 27 \\
\hline Contribution & 1,170 & 1,100 & 1,010 & 950 & 890 & 825 & 770 & 715 & 666 & 620 & 575 & 535 & 495 \\
\hline Pension: Contribution & 0.8 & 0.9 & 1.0 & 1.1 & 1.1 & 1.2 & 1.3 & 1.4 & 1.5 & 1.6 & 1.7 & 1.9 & 2.0 \\
\hline
\end{tabular}

Cite this article: Hyams SD, Smith AE, Squirrell CM, Warren GJ, Warren OH, and Willetts PJ. Saving for retirement: rules of thumb. British Actuarial Journal. https://doi.org/10.1017/S1357321720000070 